\title{
How Deregulation Shapes Market Structure and Industry Efficiency: The Case of the Italian Motor Insurance Industry
}

\author{
by Giuseppe Turchetti and Cinzia Daraio*
}

\section{The evolution of re- and de-regulation in the Italian insurance industry}

Motor insurance is the most important insurance line in Italy, accounting for about 60.4 per cent of direct non-life insurance business and for 22.3 per cent of total insurance premiums in 2002. Its nature as compulsory insurance, its influence on the inflation rate, together with the growing role played by biological damage reimbursements and by fraud, have opened a deep and sometimes harsh debate, both in the political and technical arenas, on the measures to be adopted in order to get tariff levels under control, to increase efficiency and to promote competition.

A fundamental year for the Italian insurance sector was 1912 when the Istituto Nazionale delle Assicurazioni was created and the affirmation of the principles of "authorization of admission" and of "control on tariffs" were ratified. With the transfer of control of the insurance sector to the Ministry of Industry in 1923, began a long period in which insurance companies experienced a kind of a subjection to public administration. Only from the 1970s onwards did we observe a deep process of legislation, mainly driven by the European Community directives (first, second and third generation).

The legislator's intervention introduced incentives for a shift from a strong protectionist context to a wider and free market context for insurance. In particular, 1 July 1994 was a milestone for the insurance sector. With the coming into force of the third life and non-life directives, public authorities could no longer control tariffs and insurance policy conditions. The Italian motor insurance business, traditionally strongly regulated by the government, was deeply affected. Companies started to be free to fix prices according to customers' risk attitudes, and the new tariffs system based on the bonus/malus mechanism was introduced. Seven direct selling companies were set up and services began to be improved with the opening of call centres working 24 hours a day.

Two main events occurred in 2000: the government, due to the impact of motor insurance prices on inflation, froze tariffs (Law 26/05/2000, no. 137), a decision which was censured because of its incompatibility with European laws; and the Italian Antitrust Authority sanctioned (in measure no. 8546 - I377 Bulletin no. 30, 14 August 2000) quite a

* Giuseppe Turchetti is Professor of Economics and Management, Scuola Superiore Sant'Anna, Pisa; Cinzia Daraio is post-doctoral fellow, Scuola Superiore Sant'Anna, Pisa. This article is a revised version of a paper presented to the Tenth Joint Seminar of The Geneva Association and the European Association of Law and Economics, Rotterdam, 14-15 April 2003. We would like to thank the participants of the conference for helpful discussions and suggestions. The financial and informational support of Scuola Superiore Sant'Anna and IRSA is gratefully acknowledged. 
large number of companies for violation of the competition discipline (amounting to fines of $€ 361.5$ million).

The main question addressed by our paper is if and how, over the period 1982-2000, deregulation measures influenced the structure of the supply side of the market and the efficiency and productivity of the companies operating in the Italian motor business.

In particular, we focus our attention on three main aspects:

- the effects of deregulation on the dynamics of insurers (at an aggregate level, i.e. the total number of insurers in the motor insurance market from 1982 to 2000 and the entryexit process);

- the effects of deregulation on the rate of growth of insurance activity (as measured by premiums by line of business, in particular the motor insurance business compared with non-life and life business);

- the effects of deregulation on the efficiency and productivity of a sample of Italian motor insurers.

Techniques used include Loess, to show the existence of trends in time series, and efficiency analysis methods, in particular Data Envelopment Analysis (DEA) and Malmquist analysis. DEA has been widely used in recent years to estimate efficiency in a variety of industries and national markets. ${ }^{1}$

To the best of our knowledge, this paper is the second work that applies efficiency methods to data on Italian insurers. It follows the previous work by Cummins et al. (1996) in the definition of inputs and outputs, and it gives an enriched analysis based on new data.

The paper is organized as follows. The next section describes the evolution of the number of companies, the entry-exit dynamics, the concentration ratios, the trend of premiums in the Italian insurance industry, with particular attention to the motor liability line, over the period 1982-2000. Section 3 introduces efficiency analysis by describing the sample, defining the inputs and outputs considered in the analysis, and briefly introducing the main concepts of efficiency methodology. In section 4 main results of the efficiency analysis are reported, while section 5 concludes the paper indicating future developments of research in these areas.

\section{The dynamics of the Italian insurance market structure}

Motor insurance is the most important line of business in the Italian insurance market. The fact that it is compulsory is certainly the main reason explaining both this phenomenon and the number of companies operating in the motor line. Over the period 1982-2000, always more than six out of ten insurers working in the non-life business were present in the motor line. ${ }^{2}$ The peak was reached in 1991 , with 77.40 per cent of non-life companies working in the motor business (Table 1).

The period 1982-2000 can be divided in two sub-periods, 1982-1991 and 1991-2000. While in the first period the absolute number of insurance companies operating in the motor business grew from 97 to 113 (from 69.78 per cent to 77.40 per cent, in respect of total non-

\footnotetext{
1 For a survey of 130 studies that apply frontier efficiency analysis to financial institutions in 21 countries, see Berger and Humphrey (1997).

2 Almost all companies present in the motor insurance business operate also in other non-life lines, so they are not motor specialists.
} 
Table 1:

Changes in the number of Italian insurers (direct business) by line of business $(1982-2000)^{3}$

\begin{tabular}{lccccccc}
\hline Year & RCAT & RCA_NL & RCA_TOT & TOTNL & TOTL & TOTLNL & TOTG \\
\hline 1982 & 97 & 69.78 & 62.18 & 139 & 44 & 27 & 156 \\
1983 & 95 & 69.34 & 60.51 & 137 & 47 & 27 & 157 \\
1984 & 97 & 71.32 & 61.78 & 136 & 48 & 27 & 157 \\
1985 & 95 & 71.43 & 61.29 & 133 & 49 & 27 & 155 \\
1986 & 97 & 73.48 & 62.58 & 132 & 51 & 28 & 155 \\
1987 & 98 & 73.68 & 60.49 & 133 & 57 & 28 & 162 \\
1988 & 103 & 72.54 & 57.54 & 142 & 65 & 28 & 179 \\
1989 & 109 & 75.69 & 58.60 & 144 & 70 & 28 & 186 \\
1990 & 111 & 76.03 & 57.51 & 146 & 74 & 27 & 193 \\
1991 & 113 & 77.40 & 55.94 & 146 & 83 & 27 & 202 \\
1992 & 108 & 74.48 & 51.43 & 145 & 91 & 26 & 210 \\
1993 & 106 & 71.14 & 49.07 & 149 & 92 & 25 & 216 \\
1994 & 105 & 71.92 & 48.61 & 146 & 94 & 24 & 216 \\
1995 & 99 & 68.75 & 46.05 & 144 & 93 & 22 & 215 \\
1996 & 98 & 68.06 & 44.95 & 144 & 96 & 22 & 218 \\
1997 & 94 & 71.21 & 44.98 & 132 & 98 & 21 & 209 \\
1998 & 92 & 75.41 & 46.23 & 122 & 98 & 21 & 199 \\
1999 & 87 & 66.41 & 44.39 & 131 & 96 & 31 & 196 \\
2000 & 80 & 63.49 & 41.67 & 126 & 97 & 31 & 192 \\
\hline
\end{tabular}

Source: Based on ANIA data.

life companies), in the second period a strong reduction both of the absolute number, from 113 to 80 , and of their weight in respect to total non-life companies, from 77.40 per cent to 63.49 per cent, was registered. In particular, the greater decrease is observable in the period after 1994, when the number declined from 105 to 80. Also the percentage of companies operating in the motor line over the total number of insurers present in the insurance sector declined significantly, from 62.18 per cent to 41.67 per cent, but this is explained more by the strong growth of the number of life companies (entrance of financial consultants and banks in the insurance business) than by the decline of the number of motor companies (Table 1).

The analysis of the dynamics of entries and exits from the motor business in the period 1982-2000 presents interesting results. Entries experienced an upward trend in the second half of the 1980s, but along the whole 1990s the curve was characterized by a downward slope, moderately slowed down in the years around 1994 because of the entrance of some

3 Key: RCAT (motor business); RCA_NL (no. of motor insurers over total number of insurers operating in non-life business, in percentage value); RCA_TOT (no. of motor insurers over total number of insurers, in percentage value); TOTNL (total number of insurers operating in non-life business); TOTL (total number of insurers operating in life business); TOTLNL (total number of insurers operating in life and non-life business); TOTG (total number of insurers). Note: TOTG is computed as follows: TOTNL+TOTL-TOTLNL. 


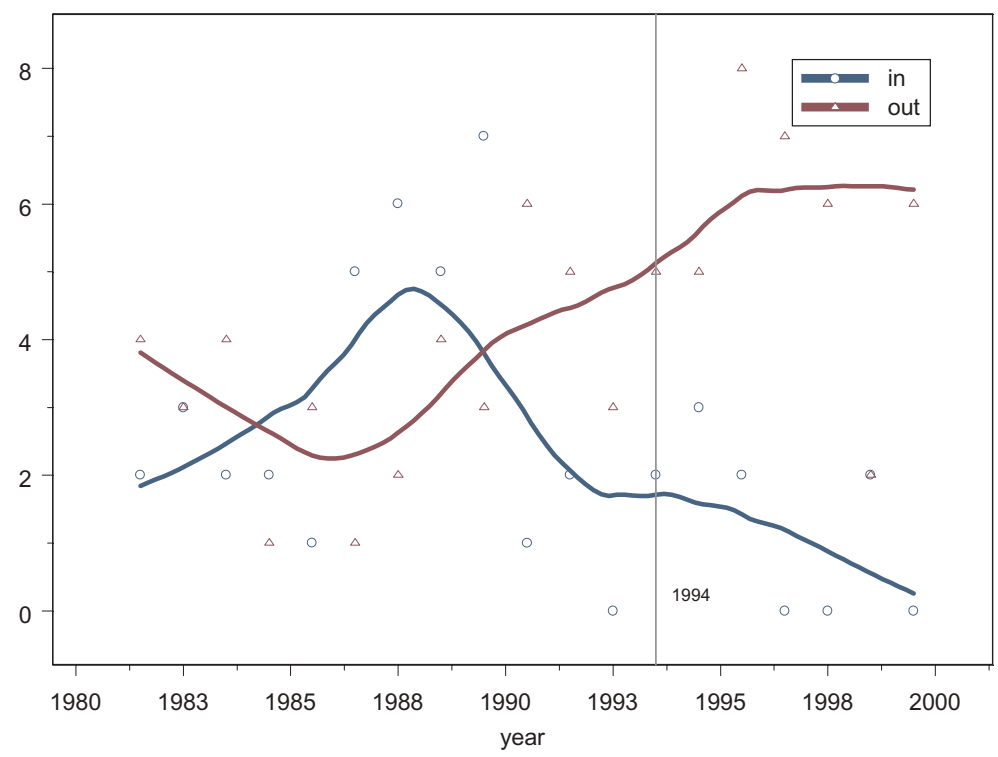

Figure 1: Trend of entries (in)-exits (out) from the motor insurance market (1982-2000) ${ }^{4}$

companies using the telephone as the distribution channel. Exits experienced the opposite: at the beginning of the period we observe a downward slope of the curve, but from the late 1980 s the trend started to rise and it increased for the whole 1990s. Certainly the number of exits began to grow much earlier than 1994, but around that year the slope of the curve was particularly significant.

Table 2 presents concentration ratios of Italian motor insurance business, of total nonlife business and of life business in the period 1982-2000. Data of motor and of non-life markets do not show significant variation of concentration of the first four, eight and 20 companies during the last 20 years, especially after 1994. Also the Herfindahl Index does not evidence variations of the concentration of the two mentioned markets during the period analysed. The life market instead presents a relevant reduction of the concentration, due to the important role conquered by new entrants using financial consultants and bank branches.

Regarding the real rates of growth of gross premiums (direct business) in the period 1992-2001, it is interesting to note that the motor business has experienced a series of ups and downs until the first half of 1990s, with a downward convergence in the 1992-1994 period, and that after the deregulation period, the premiums rate of growth started to increase again (halting in 2000 and 2001, when the government imposed a price freeze on motor third-party liability) (Figure 2). This is particularly significant because the real rate of growth of premiums of other non-life lines continued to decline also after 1994. On the other

4 Figures 1 and 2 were designed using a locally weighted least-squares (Loess) technique (see Cleveland, 1993, 1994). 
Table 2:

Concentration ratios for the Italian motor insurance industry and for total non-life business (1982-2000) C4, C8, C20 are in percentage values

\begin{tabular}{|c|c|c|c|c|c|c|c|c|c|c|c|c|}
\hline \multirow[b]{2}{*}{ Year } & \multicolumn{4}{|c|}{ Non-life premiums } & \multicolumn{4}{|c|}{ Motor premiums } & \multicolumn{4}{|c|}{ Life premiums } \\
\hline & $\mathrm{C} 4$ & C8 & $\mathrm{C} 20$ & Herf & $\mathrm{C} 4$ & C8 & $\mathrm{C} 20$ & Herf & $\mathrm{C} 4$ & C8 & $\mathrm{C20}$ & Herf \\
\hline 1982 & 30.438 & 43.193 & 63.626 & 0.033 & 27.256 & 41.724 & 67.124 & 0.033 & 71.032 & 83.609 & 93.952 & 0.146 \\
\hline 1983 & 29.770 & 42.814 & 63.257 & 0.033 & 26.877 & 41.511 & 66.612 & 0.032 & 70.951 & 83.026 & 93.829 & 0.146 \\
\hline 1984 & 29.586 & 42.757 & 63.308 & 0.033 & 26.820 & 41.855 & 66.302 & 0.032 & 69.722 & 81.815 & 93.260 & 0.145 \\
\hline 1985 & 28.989 & 42.416 & 62.868 & 0.032 & 26.225 & 41.180 & 64.884 & 0.031 & 66.821 & 78.731 & 92.483 & 0.137 \\
\hline 1986 & 29.028 & 42.523 & 62.643 & 0.032 & 25.967 & 40.872 & 63.900 & 0.031 & 64.720 & 77.320 & 91.687 & 0.133 \\
\hline 1987 & 29.261 & 42.834 & 62.873 & 0.032 & 25.774 & 40.941 & 63.478 & 0.030 & 60.456 & 73.682 & 89.583 & 0.117 \\
\hline 1988 & 29.569 & 43.073 & 63.020 & 0.032 & 25.596 & 40.871 & 62.825 & 0.030 & 58.324 & 71.889 & 88.249 & 0.111 \\
\hline 1989 & 30.183 & 44.325 & 68.596 & 0.035 & 26.020 & 42.835 & 69.082 & 0.033 & 56.193 & 70.383 & 87.836 & 0.101 \\
\hline 1990 & 30.118 & 44.360 & 67.384 & 0.035 & 25.976 & 42.557 & 67.596 & 0.032 & 54.651 & 68.728 & 86.503 & 0.095 \\
\hline 1991 & 29.755 & 45.593 & 67.926 & 0.035 & 26.107 & 43.350 & 68.343 & 0.033 & 52.486 & 66.879 & 85.759 & 0.088 \\
\hline 1992 & 29.595 & 45.492 & 67.712 & 0.035 & 25.816 & 43.592 & 68.565 & 0.033 & 49.299 & 63.516 & 83.028 & 0.077 \\
\hline 1993 & 29.792 & 45.776 & 67.676 & 0.035 & 26.064 & 43.859 & 69.152 & 0.034 & 45.391 & 59.399 & 78.856 & 0.066 \\
\hline 1994 & 29.669 & 49.304 & 73.617 & 0.039 & 28.557 & 48.767 & 75.873 & 0.039 & 41.590 & 55.848 & 75.664 & 0.058 \\
\hline 1995 & 29.888 & 49.286 & 73.510 & 0.040 & 27.877 & 48.833 & 75.829 & 0.039 & 40.054 & 53.577 & 74.958 & 0.054 \\
\hline 1996 & 29.486 & 48.567 & 73.017 & 0.039 & 27.580 & 48.087 & 75.349 & 0.039 & 38.135 & 50.715 & 72.266 & 0.050 \\
\hline 1997 & 29.358 & 47.711 & 72.599 & 0.038 & 26.249 & 46.655 & 74.280 & 0.037 & 32.136 & 46.830 & 69.737 & 0.039 \\
\hline 1998 & 30.958 & 48.862 & 78.022 & 0.042 & 27.758 & 47.248 & 80.118 & 0.040 & 28.024 & 44.331 & 71.279 & 0.036 \\
\hline 1999 & 30.752 & 47.543 & 77.175 & 0.040 & 27.900 & 46.149 & 78.851 & 0.039 & 24.823 & 39.705 & 66.089 & 0.030 \\
\hline 2000 & 30.254 & 47.181 & 76.870 & 0.040 & 27.690 & 46.187 & 78.875 & 0.039 & 23.368 & 38.234 & 66.319 & 0.029 \\
\hline
\end{tabular}

Source: Based on ANIA data. 


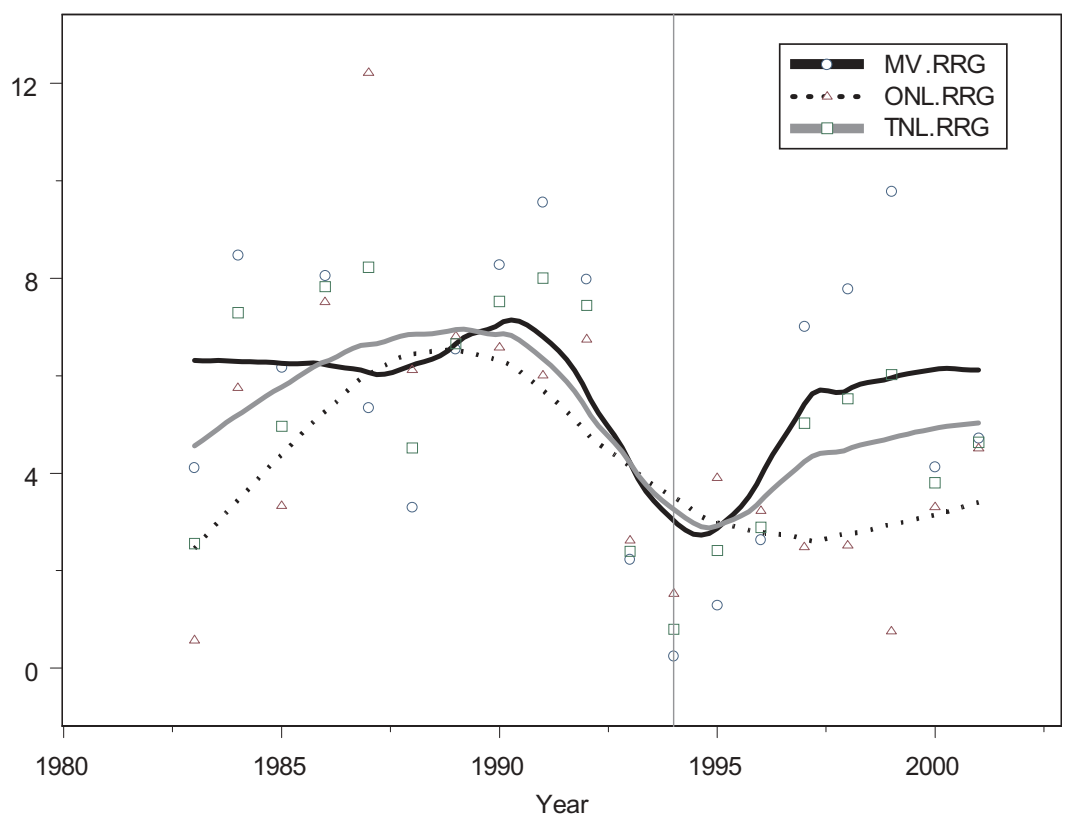

Figure 2: Real rate of growth - gross premiums (direct business) non-life business $(1982-2001)^{8}$

side, the real rate of growth of premiums of life business increased for the whole 1982-2001 period in a very sustained way.

While the high relevant growth of life business can be explained by a series of economic, financial, social and industrial factors, it is interesting to note the difference in the evolution of the growth of motor business in comparison with the growth of other non-life lines. In fact, as most of them are mature lines, we should have expected them to experience similar movement.

Actually, as claimed by some researchers and insurance operators, the increase in motor premiums after 1994 can be explained by a series of factors. Firstly, the total number of vehicles increased in the period 1994-2001 from 39,755,000 to 46,480,000. ${ }^{5}$ Secondly, the average premium might have grown (increasing by 53.5 per cent in the period 1994$2001^{6}$ ) because the vehicles insured changed to high-powered cars and to turbo and diesel vehicles, as well as clients' tendency to ask for higher sums insured.

Among the causes that could explain the rise in tariffs in the motor business in the 1990 s that are particularly mentioned in the debate are: ${ }^{7}$ (a) the increase in the average cost of compensations for damage, which almost doubled from $€ 1,923$ to $€ 3,830$ between 1994

5 Source: Automobile Club Italia.

6 Source: Assicurazioni Generali (2003).

7 Data reported are from Assicurazioni Generali (2003).

8 Key: MV.RRG: motor vehicles premiums' real rate of growth; ONL.RRG: other non-life premiums' real rate of growth; TNL.RRG: total non-life premiums' real rate of growth. 
and 2001; (b) the rapid rise in the cost of repairs; (c) the outstanding frequency of cervical spine lesions, that are typical of the Italian system (in Italy 66 per cent of reported claims relate to such lesions as against 40 per cent in Germany, 15 per cent in Spain, and 6 per cent in France); (d) the frequency of fraud.

\section{The dynamics of productivity and efficiency in the Italian motor insurance industry (1982-2000)}

\subsection{Sample description}

Our database consists of financial statements for almost all insurers operating in Italy over the period 1982-2000 and it is based on official data from the Italian Association of Insurance Companies.

In our empirical analysis we selected insurers operating in Italy, active and working in the motor liability sector during the whole period 1982-2000. The number of retained companies was 53 from which we excluded several companies for some negative values in outputs, obtaining a final sample useful for the analysis of 45 insurers. The 66.7 per cent of our sample (30 insurers) are made of generalist insurers, the remaining 33.3 per cent (15 firms) are active only in the non-life business.

Premiums collected by the companies in our sample over total premiums (direct business) in the motor business for the whole period under consideration (1982-2000) range from a minimum of 59.45 per cent in 1986 to a maximum of 77.89 per cent in 1999 . On average (1982-2000), our sample represents 64.52 per cent of the Italian motor insurance market.

As already mentioned, in 2000 the Italian Antitrust Authority sanctioned quite a large number of companies for information exchange. Twenty-seven companies out of the 45 that make up our sample have been hit by this antitrust measure. Among these, 12 are active only in non-life business (specialists) and 15 are active both in life and non-life business (generalists).

Using this dataset, we analysed the dynamics of productivity and efficiency of the most representative Italian insurers active in the motor business over the period 1982-2000.

\subsection{Definition of outputs and inputs}

As they produce services, insurers are analogous to other financial firms. Consistent with most of the recent literature on financial institutions, for the measurement of output we adopt a modified version of the value-added approach, which counts as important outputs those that have significant value added, as judged using operating cost allocations (Berger and Humphrey, 1992; Cummins et al., 1996; Cummins and Rubio-Misas, 2001). Insurers provide three principal services:

1. Risk-pooling and risk-bearing. Insurance provides a mechanism through which consumers and businesses exposed to losses can engage in risk reduction through pooling. The actuarial, underwriting, and related expenses incurred in risk pooling are important components of value added in the industry. Insurers also add value by holding equity capital to bear the residual risk of the pool.

2. "Real" financial services relating to insured losses. Insurers provide a variety of real services for policyholders including financial planning, risk management, and the supply of legal defence in liability disputes. By contracting with insurers to provide 
these services, policyholders take advantage of insurers' specialized expertise to reduce the costs associated with managing risks.

3. Intermediation. For life insurers, financial intermediation is a principal function, accomplished through the sale of asset accumulation products such as annuities. For non-life insurers, intermediation is an important but incidental function, resulting from the collection of premiums in advance of claim payments. Insurers' value added from intermediation is reflected in the net interest margin between the rate of return earned on invested assets and the rate credited to policyholders.

Transactions flow data, such as the number of applications processed, policies issued, and claims settled, are not readily available. However, a satisfactory proxy for the amount of risk-pooling and real insurance services provided is the value of real losses incurred (Skogh, 1982; Cummins et al., 1996; Berger et al., 1997; Cummins and Weiss, Zi, 1999). Losses incurred are defined as the losses that are expected to be paid as the result of providing insurance coverage during a particular period of time. Because the objective of risk-pooling is to collect funds from the policyholder pool and redistribute them to those who incur losses, proxying output by the amount of losses incurred seems quite appropriate. Losses are also a good proxy for the amount of real services provided, since the amount of claims settlement and risk management services are also highly correlated with loss aggregates. Because types of services provided differ among the principal lines of insurance, and following a previous study on the Italian insurance efficiency (Cummins et al., 1996), we use as separate output measures the value of several non-life insurance losses incurred,

Table 3:

Inputs and outputs

\begin{tabular}{ll}
\hline Inputs & \multicolumn{1}{c}{ Price $^{9}$} \\
\hline $\begin{array}{l}\text { 1. Acquisition production and } \\
\text { organization costs }\end{array}$ & $\begin{array}{l}\text { Value added of credit and insurance at } 1995 \\
\text { market price }\end{array}$ \\
2. Overheads and administrative expenses & $\begin{array}{l}\text { Value added of credit and insurance at } 1995 \\
\text { market price }\end{array}$ \\
3. Fixed capital & $\begin{array}{l}\text { Government bond yield (long-term) } \\
\text { 4. Financial equity capital }\end{array}$ \\
5. Policyholder debt capital & Government bond yield (long-term)
\end{tabular}

\section{Outputs}

1. Motor property incurred losses

2. Motor liability incurred losses

3. Other liabilities incurred losses

4. Other properties incurred losses

5. Invested assets

\footnotetext{
9 According to previous studies and the international literature, prices are considered equal for all insurers.
} 
distinguishing between motor property, motor liability, other liabilities, and other properties.

Losses incurred and all other monetary values used in our analysis are expressed in 1982 monetary units by deflating the Italian Consumer Price Index (source: Bank of Italy). Losses incurred are a satisfactory measure of output for coverage provided during any given year. However, insurers also perform services in connection with claims occurring in previous years that have not yet been settled or claims resulting from contingent events. As a proxy for these services, in the definition of each output we consider, for each year, the sum of the paid claims (for the line of business considered) and the claims reserves of the year, minus the claims reserves of the previous year. By doing so, in the definition of the outputs, we consider as proxy of financial services the sum of paid claims and changes in reserves. Our final output variable, which represents a proxy for the intermediation function, is the real value of invested assets.

In defining inputs of insurance activity, we follow Cummins et al. (1996) and the recent insurance efficiency literature. We identify five inputs:

- agents labour and distribution expense (acquisition, production and organization costs);

- overheads and administrative expenses;

- fixed capital (physical capital and other business expenses);

- financial equity capital;

— policyholder debt capital (reserves, all kinds).

\subsection{Methodology}

To measure efficiency in the Italian motor insurance industry, we utilize modern frontier efficiency analysis, in particular DEA and Malmquist analysis. ${ }^{10}$ DEA is a nonparametric technique that does not require the specification of a production or cost function but rather computes efficient "best practice" production and cost frontiers based on linear combinations of firms in the industry. DEA involves the measurement of the performance of each firm in the industry compared to "best practice" efficient frontiers. The comparison is based on relevant inputs and outputs of the financial service provided by the companies.

Efficiency scores vary between zero and one (in the input-oriented framework applied in this study), with fully efficient firms having efficiencies equal to one and inefficient firms having efficiencies between zero and one. This section provides a brief overview of the basic concept of frontier efficiency methodology.

We estimate efficient production and cost frontiers providing measures of cost, technical, allocative and scale efficiency for each firm in our sample.

Cost efficiency for a given firm is defined as the ratio of the costs of a fully efficient firm (a firm operating on the efficient cost frontier) with the same output quantities and input prices to the given firm's actual costs. One minus the firm efficiency ratio provides a measure of the proportion by which costs could be reduced if the firm operated on the cost frontier. Firms achieve cost efficiency by adopting the best practice technology (becoming

10 Starting from the first empirical application by Farrell (1957), a huge amount of literature on efficiency analysis has been developed. For more technical details on DEA see the "classical" works by Lovell (1993); Charnes et al. (1994). For an updated survey on DEA models see Cooper et al. (1999). For an introduction to Malmquist Analysis see Grosskopf (1993). 
technically efficient) and choosing the optimal mix of inputs (becoming allocatively efficient), conditional on outputs and input prices.

Technical efficiency for a given firm is defined as the ratio of the inputs use of a fully efficient firm producing the same outputs vector to the inputs use of the firm under consideration. Technical efficiency can be decomposed into pure technical efficiency and scale efficiency. Pure technical efficiency is measured relative to variable returns to scale (VRS) production frontier, i.e. a frontier characterized by increasing, constant, and/or decreasing returns to scale. Firms operating on the VRS frontier are considered fully efficient in the pure technical sense. If the firm is operating with increasing or decreasing returns to scale, it can improve its efficiency by moving to a constant returns to scale frontier, i.e. by becoming scale efficient. Technical efficiency is equal to the product of pure technical and scale efficiency.

Allocative efficiency measures firm success in choosing the cost-minimizing combination of inputs. Cost efficiency can be shown to equal the product of technical and allocative efficiency. Therefore, to be fully cost efficient, a firm must be both technically and allocatively efficient.

The Malmquist approach measures both improvements in technology and changes in efficiency relative to the frontiers for different time periods. Malmquist analysis allows us to separate shifts in the frontier (technical change) from improvements in efficiency relative to the frontier (technical efficiency change). The product of technical change and technical efficiency change, the total factor productivity change (TFP), is measured by the Malmquist Index (Grosskopf, 1993).

If a Malmquist Index computed over two years is over 1, it indicates an increase in total factor productivity from year $t$ to year $(t+1)$; if it is under 1 then it indicates a decrease in total factor productivity. The same interpretation applies for technical change (technical efficiency change): if the value of the index is higher than 1 , there has been an improvement in technology (technical efficiency) from year $t$ to year $(t+1)$; on the other hand, if its value is lower than 1 , that means that a deterioration in technology is in place from year $t$ to year $(t+1)$.

\section{Results of efficiency and productivity analysis}

Efficiency results presented in Table 4 show average efficiencies for the entire sample as well as distinguishing between companies hit by the antitrust measure $(\mathrm{FINED}=1)$ and companies not hit by the Antitrust measure $(\mathrm{FINED}=0)$. Averages are shown for cost efficiency and its components (allocative efficiency and pure technical efficiency, computed under the hypothesis of VRS).

Cost efficiency of the 45 companies active for the whole period experienced a fall in 1994 (and we had also the highest value of standard deviation), but after that year it increased again, reaching almost the same level of cost efficiency observed in 1990. On the one hand, the confusion and the reorganization processes that occurred around 1994 produced a considerable loss of cost efficiency. In 1995, for example, costs could have been reduced on average by 21 per cent if companies had operated on the cost frontier. On the other hand, we observe a level of technical efficiency (under VRS) that was extremely high on average over the whole period 1982-2000.

Another interesting observation is that fined firms present higher levels of cost efficiency, allocative efficiency, pure technical and scale efficiency in respect to non-fined companies during almost the whole period. Moreover, among the companies fined (27 
Table 4:

Cost efficiency, allocative efficiency, technical efficiency (VRS) and scale efficiency. All sample (45 obs), FINED=1 (27 obs), FINED=0 (18 obs)

\begin{tabular}{|c|c|c|c|c|c|c|c|c|c|c|}
\hline \multirow[b]{2}{*}{ year } & \multicolumn{5}{|c|}{ All sample (45 obs) } & \multicolumn{5}{|c|}{ Only FINED $=1$ companies $(27 \mathrm{obs})$} \\
\hline & statistics & Cost eff & Alloc eff & $\begin{array}{l}\text { tech eff } \\
\text { VRS }\end{array}$ & Scale eff & statistics & cost eff & alloc eff & $\begin{array}{l}\text { tech eff } \\
\text { VRS }\end{array}$ & Scale eff \\
\hline \multirow[t]{4}{*}{1982} & Mean(82) & 0.68 & 0.7 & 0.96 & 0.94 & mean & 0.71 & 0.73 & 0.96 & 0.94 \\
\hline & stdev & 0.26 & 0.25 & 0.07 & 0.09 & stdev & 0.27 & 0.25 & 0.08 & 0.08 \\
\hline & $\min$ & 0.25 & 0.25 & 0.67 & 0.63 & $\min$ & 0.32 & 0.36 & 0.67 & 0.72 \\
\hline & $\max$ & 1 & 1 & 1 & 1.00 & $\max$ & 1 & 1 & 1 & 1.00 \\
\hline \multirow[t]{4}{*}{1983} & $\operatorname{Mean}(83)$ & 0.71 & 0.73 & 0.97 & 0.97 & mean & 0.74 & 0.76 & 0.98 & 0.96 \\
\hline & stdev & 0.25 & 0.24 & 0.06 & 0.04 & stdev & 0.25 & 0.24 & 0.06 & 0.05 \\
\hline & $\min$ & 0.33 & 0.33 & 0.75 & 0.78 & $\min$ & 0.33 & 0.33 & 0.75 & 0.78 \\
\hline & $\max$ & 1.00 & 1.00 & 1.00 & 1.00 & $\max$ & 1.00 & 1.00 & 1.00 & 1.00 \\
\hline 1984 & Mean(84) & 0.75 & 0.76 & 0.98 & 0.98 & mean & 0.79 & 0.81 & 0.98 & 0.98 \\
\hline & stdev & 0.24 & 0.23 & 0.04 & 0.05 & stdev & 0.23 & 0.21 & 0.05 & 0.05 \\
\hline & $\min$ & 0.33 & 0.35 & 0.81 & 0.78 & $\min$ & 0.41 & 0.41 & 0.81 & 0.78 \\
\hline & $\max$ & 1.00 & 1.00 & 1.00 & 1.00 & $\max$ & 1.00 & 1.00 & 1.00 & 1.00 \\
\hline 1985 & Mean(85) & 0.76 & 0.78 & 0.96 & 0.98 & mean & 0.82 & 0.83 & 0.98 & 0.98 \\
\hline & stdev & 0.22 & 0.21 & 0.08 & 0.05 & stdev & 0.19 & 0.18 & 0.04 & 0.04 \\
\hline & $\min$ & 0.24 & 0.37 & 0.65 & 0.76 & $\min$ & 0.43 & 0.45 & 0.87 & 0.82 \\
\hline & $\max$ & 1 & 1 & 1 & 1.00 & $\max$ & 1 & 1 & 1 & 1.00 \\
\hline 1986 & Mean(86) & 0.78 & 0.80 & 0.97 & 0.98 & mean & 0.83 & 0.84 & 0.98 & 0.99 \\
\hline & stdev & 0.21 & 0.20 & 0.06 & 0.05 & stdev & 0.19 & 0.18 & 0.03 & 0.03 \\
\hline & $\min$ & 0.42 & 0.43 & 0.77 & 0.73 & $\min$ & 0.43 & 0.43 & 0.89 & 0.84 \\
\hline & $\max$ & 1.00 & 1.00 & 1.00 & 1.00 & $\max$ & 1.00 & 1.00 & 1.00 & 1.00 \\
\hline 1987 & Mean(87) & 0.77 & 0.79 & 0.97 & 0.98 & mean & 0.83 & 0.84 & 0.99 & 0.98 \\
\hline & stdev & 0.21 & 0.20 & 0.06 & 0.04 & stdev & 0.17 & 0.17 & 0.03 & 0.03 \\
\hline & $\min$ & 0.34 & 0.34 & 0.73 & 0.83 & $\min$ & 0.46 & 0.46 & 0.89 & 0.84 \\
\hline & $\max$ & 1.00 & 1.00 & 1.00 & 1.00 & $\max$ & 1.00 & 1.00 & 1.00 & 1.00 \\
\hline 1988 & Mean(88) & 0.78 & 0.82 & 0.96 & 0.97 & mean & 0.84 & 0.86 & 0.97 & 0.99 \\
\hline & stdev & 0.19 & 0.18 & 0.08 & 0.07 & stdev & 0.18 & 0.17 & 0.05 & 0.03 \\
\hline & $\min$ & 0.44 & 0.44 & 0.69 & 0.60 & $\min$ & 0.44 & 0.44 & 0.83 & 0.86 \\
\hline & $\max$ & 1.00 & 1.00 & 1.00 & 1.00 & $\max$ & 1.00 & 1.00 & 1.00 & 1.00 \\
\hline 1989 & Mean(89) & 0.82 & 0.84 & 0.98 & 0.98 & mean & 0.86 & 0.87 & 0.98 & 0.99 \\
\hline & stdev & 0.16 & 0.15 & 0.05 & 0.04 & stdev & 0.15 & 0.14 & 0.04 & 0.03 \\
\hline & $\min$ & 0.50 & 0.50 & 0.71 & 0.85 & $\min$ & 0.52 & 0.52 & 0.85 & 0.85 \\
\hline & $\max$ & 1.00 & 1.00 & 1.00 & 1.00 & $\max$ & 1.00 & 1.00 & 1.00 & 1.00 \\
\hline 1990 & $\operatorname{Mean}(90)$ & 0.81 & 0.83 & 0.98 & 0.99 & mean & 0.82 & 0.83 & 0.98 & 0.99 \\
\hline & stdev & 0.19 & 0.17 & 0.06 & 0.02 & stdev & 0.18 & 0.17 & 0.04 & 0.02 \\
\hline & $\min$ & 0.47 & 0.47 & 0.73 & 0.88 & $\min$ & 0.47 & 0.47 & 0.84 & 0.88 \\
\hline & $\max$ & 1 & 1 & 1 & 1.00 & $\max$ & 1 & 1 & 1 & 1.00 \\
\hline 1991 & Mean(91) & 0.85 & 0.85 & 0.99 & 1.00 & mean & 0.87 & 0.87 & 1.00 & 1.00 \\
\hline & stdev & 0.16 & 0.16 & 0.02 & 0.01 & stdev & 0.15 & 0.15 & 0.02 & 0.00 \\
\hline & $\min$ & 0.51 & 0.52 & 0.89 & 0.94 & $\min$ & 0.55 & 0.56 & 0.94 & 0.99 \\
\hline & $\max$ & 1.00 & 1.00 & 1.00 & 1.00 & $\max$ & 1.00 & 1.00 & 1.00 & 1.00 \\
\hline 1992 & $\operatorname{Mean}(92)$ & 0.87 & 0.87 & 0.99 & 0.99 & mean & 0.88 & 0.89 & 1.00 & 1.00 \\
\hline & stdev & 0.14 & 0.14 & 0.03 & 0.02 & stdev & 0.13 & 0.13 & 0.02 & 0.01 \\
\hline & $\min$ & 0.56 & 0.56 & 0.86 & 0.88 & $\min$ & 0.64 & 0.64 & 0.91 & 0.97 \\
\hline & $\max$ & 1.00 & 1.00 & 1.00 & 1.00 & $\max$ & 1.00 & 1.00 & 1.00 & 1.00 \\
\hline 1993 & Mean(93) & 0.82 & 0.84 & 0.98 & 0.99 & mean & 0.86 & 0.86 & 0.99 & 0.99 \\
\hline & stdev & 0.17 & 0.16 & 0.07 & 0.02 & stdev & 0.16 & 0.15 & 0.02 & 0.03 \\
\hline & $\min$ & 0.51 & 0.52 & 0.63 & 0.87 & $\min$ & 0.52 & 0.52 & 0.88 & 0.87 \\
\hline & $\max$ & 1.00 & 1.00 & 1.00 & 1.00 & $\max$ & 1.00 & 1.00 & 1.00 & 1.00 \\
\hline 1994 & Mean(94) & 0.52 & 0.53 & 0.97 & 0.98 & mean & 0.56 & 0.56 & 0.98 & 0.98 \\
\hline & stdev & 0.3 & 0.3 & 0.07 & 0.04 & stdev & 0.32 & 0.32 & 0.04 & 0.05 \\
\hline & $\min$ & 0.19 & 0.19 & 0.65 & 0.84 & $\min$ & 0.19 & 0.19 & 0.82 & 0.84 \\
\hline & $\max$ & 1 & 1 & 1 & 1.00 & $\max$ & 1 & 1 & 1 & 1.00 \\
\hline 1995 & Mean(95) & 0.79 & 0.82 & 0.97 & 0.98 & mean & 0.80 & 0.84 & 0.96 & 0.98 \\
\hline & stdev & 0.18 & 0.17 & 0.07 & 0.05 & stdev & 0.17 & 0.16 & 0.07 & 0.05 \\
\hline & $\min$ & 0.43 & 0.45 & 0.73 & 0.82 & $\min$ & 0.43 & 0.45 & 0.73 & 0.82 \\
\hline & $\max$ & 1.00 & 1.00 & 1.00 & 1.00 & $\max$ & 1.00 & 1.00 & 1.00 & 1.00 \\
\hline 1996 & $\operatorname{Mean}(96)$ & 0.84 & 0.86 & 0.98 & 0.97 & mean & 0.84 & 0.86 & 0.97 & 0.97 \\
\hline & stdev & 0.17 & 0.16 & 0.05 & 0.07 & stdev & 0.17 & 0.15 & 0.06 & 0.06 \\
\hline & $\min$ & 0.40 & 0.48 & 0.78 & 0.64 & $\min$ & 0.40 & 0.48 & 0.78 & 0.71 \\
\hline & $\min$ & 1.00 & 1.00 & 1.00 & 1.00 & $\min$ & 1.00 & 1.00 & 1.00 & 1.00 \\
\hline 1997 & Mean(97) & 0.82 & 0.84 & 0.98 & 0.96 & mean & 0.84 & 0.85 & 0.98 & 0.95 \\
\hline & stdev & 0.19 & 0.18 & 0.05 & 0.08 & stdev & 0.19 & 0.18 & 0.06 & 0.10 \\
\hline & $\min$ & 0.21 & 0.21 & 0.74 & 0.57 & $\min$ & 0.21 & 0.21 & 0.74 & 0.57 \\
\hline & $\min$ & 1.00 & 1.00 & 1.00 & 1.00 & $\min$ & 1.00 & 1.00 & 1.00 & 1.00 \\
\hline 1998 & Mean(98) & 0.75 & 0.76 & 0.98 & 0.99 & mean & 0.80 & 0.81 & 0.99 & 0.99 \\
\hline & stdev & 0.21 & 0.20 & 0.05 & 0.03 & stdev & 0.17 & 0.17 & 0.03 & 0.02 \\
\hline & $\min$ & 0.20 & 0.20 & 0.78 & 0.84 & $\min$ & 0.43 & 0.43 & 0.89 & 0.90 \\
\hline & $\min$ & 1.00 & 1.00 & 1.00 & 1.00 & $\min$ & 1.00 & 1.00 & 1.00 & 1.00 \\
\hline 1999 & Mean(99) & 0.82 & 0.83 & 0.99 & 0.99 & mean & 0.84 & 0.84 & 0.99 & 0.99 \\
\hline & stdev & 0.18 & 0.17 & 0.03 & 0.03 & stdev & 0.16 & 0.16 & 0.02 & 0.03 \\
\hline & $\min$ & 0.41 & 0.49 & 0.85 & 0.86 & $\min$ & 0.51 & 0.51 & 0.91 & 0.86 \\
\hline & $\min$ & 1.00 & 1.00 & 1.00 & 1.00 & $\min$ & 1.00 & 1.00 & 1.00 & 1.00 \\
\hline 2000 & $\operatorname{Mean}(00)$ & 0.84 & 0.84 & 0.99 & 0.98 & mean & 0.87 & 0.88 & 0.99 & 0.97 \\
\hline & stdev & 0.18 & 0.17 & 0.03 & 0.06 & stdev & 0.15 & 0.14 & 0.04 & 0.05 \\
\hline & $\min$ & 0.48 & 0.48 & 0.84 & 0.72 & $\min$ & 0.48 & 0.48 & 0.84 & 0.76 \\
\hline & $\min$ & 1 & 1 & 1 & 1.00 & $\min$ & 1 & 1 & 1 & 1.00 \\
\hline
\end{tabular}




\begin{tabular}{|c|c|c|c|c|c|c|c|c|c|c|c|c|c|c|}
\hline \multicolumn{5}{|c|}{ Only FINED $=0$ companies $(18$ obs $)$} & \multicolumn{5}{|c|}{ Only FINED $=1$ Generalist $(15 \mathrm{obs})$} & \multicolumn{5}{|c|}{ Only FINED=1 Specialist (12 obs.) } \\
\hline statistics & cost eff & alloc eff & $\begin{array}{l}\text { tech eff } \\
\text { (VRS) }\end{array}$ & Scale eff & & cost eff & alloc eff & $\begin{array}{l}\text { tech eff } \\
\text { (VRS) }\end{array}$ & Scale eff & & cost eff & alloc eff & $\begin{array}{l}\text { Tech eff } \\
\text { (VRS) }\end{array}$ & Scale eff \\
\hline mean & 0.63 & 0.65 & 0.96 & 0.94 & mean & 0.86 & 0.88 & 0.97 & 0.92 & mean & 0.53 & 0.55 & 0.96 & 0.96 \\
\hline stdev & 0.25 & 0.24 & 0.05 & 0.10 & stdev & 0.22 & 0.20 & 0.07 & 0.09 & stdev & 0.23 & 0.22 & 0.06 & 0.05 \\
\hline $\min$ & 0.25 & 0.25 & 0.85 & 0.63 & $\min$ & 0.36 & 0.36 & 0.75 & 0.72 & $\min$ & 0.32 & 0.36 & 0.8 & 0.86 \\
\hline $\max$ & 1 & 1 & 1 & 1.00 & $\max$ & 1.00 & 1.00 & 1.00 & 1.00 & $\max$ & 1 & 1 & 1 & 1.00 \\
\hline mean & 0.67 & 0.69 & 0.96 & 0.99 & mean & 0.89 & 0.90 & 0.99 & 0.95 & mean & 0.60 & 0.61 & 0.98 & 0.98 \\
\hline stdev & 0.23 & 0.23 & 0.06 & 0.02 & stdev & 0.19 & 0.18 & 0.04 & 0.06 & stdev & 0.21 & 0.20 & 0.04 & 0.03 \\
\hline $\min$ & 0.33 & 0.34 & 0.82 & 0.95 & $\min$ & 0.41 & 0.41 & 0.84 & 0.78 & $\min$ & 0.33 & 0.33 & 0.85 & 0.92 \\
\hline $\max$ & 1.00 & 1.00 & 1.00 & 1.00 & $\max$ & 1.00 & 1.00 & 1.00 & 1.00 & $\max$ & 1.00 & 1.00 & 1.00 & 1.00 \\
\hline mean & 0.68 & 0.70 & 0.98 & 0.98 & mean & 0.89 & 0.90 & 0.99 & 0.97 & mean & 0.67 & 0.69 & 0.97 & 1.00 \\
\hline stdev & 0.23 & 0.23 & 0.03 & 0.05 & stdev & 0.19 & 0.18 & 0.04 & 0.06 & stdev & 0.21 & 0.20 & 0.06 & 0.01 \\
\hline $\min$ & 0.33 & 0.35 & 0.91 & 0.78 & $\min$ & 0.41 & 0.41 & 0.84 & 0.78 & $\min$ & 0.42 & 0.44 & 0.81 & 0.97 \\
\hline $\max$ & 1.00 & 1.00 & 1.00 & 1.00 & $\max$ & 1.00 & 1.00 & 1.00 & 1.00 & $\max$ & 1.00 & 1.00 & 1.00 & 1.00 \\
\hline mean & 0.66 & 0.7 & 0.93 & 0.97 & Mean & 0.9 & 0.91 & 0.99 & 0.96 & mean & 0.72 & 0.74 & 0.97 & 0.99 \\
\hline stdev & 0.23 & 0.21 & 0.1 & 0.06 & stdev & 0.16 & 0.15 & 0.03 & 0.05 & stdev & 0.19 & 0.18 & 0.04 & 0.01 \\
\hline $\min$ & 0.24 & 0.37 & 0.65 & 0.76 & Min & 0.5 & 0.5 & 0.87 & 0.82 & $\min$ & 0.43 & 0.45 & 0.88 & 0.96 \\
\hline $\max$ & 1 & 1 & 1 & 1.00 & $\operatorname{Max}$ & 1 & 1 & 1 & 1.00 & $\max$ & 1 & 1 & 1 & 1.00 \\
\hline mean & 0.70 & 0.73 & 0.95 & 0.97 & mean & 0.89 & 0.90 & 0.99 & 0.98 & mean & 0.76 & 0.77 & 0.98 & 1.00 \\
\hline stdev & 0.22 & 0.20 & 0.08 & 0.06 & stdev & 0.18 & 0.17 & 0.03 & 0.04 & stdev & 0.18 & 0.17 & 0.04 & 0.01 \\
\hline $\min$ & 0.42 & 0.45 & 0.77 & 0.73 & $\min$ & 0.47 & 0.48 & 0.91 & 0.84 & $\min$ & 0.43 & 0.43 & 0.89 & 0.98 \\
\hline $\max$ & 1.00 & 1.00 & 1.00 & 1.00 & $\max$ & 1.00 & 1.00 & 1.00 & 1.00 & $\max$ & 1.00 & 1.00 & 1.00 & 1.00 \\
\hline mean & 0.68 & 0.72 & 0.94 & 0.97 & mean & 0.87 & 0.88 & 0.99 & 0.97 & mean & 0.78 & 0.79 & 0.99 & 1.00 \\
\hline stdev & 0.23 & 0.21 & 0.08 & 0.05 & stdev & 0.17 & 0.17 & 0.03 & 0.04 & stdev & 0.16 & 0.16 & 0.03 & 0.00 \\
\hline $\min$ & 0.34 & 0.34 & 0.73 & 0.83 & $\min$ & 0.53 & 0.53 & 0.90 & 0.84 & $\min$ & 0.46 & 0.46 & 0.89 & 0.99 \\
\hline $\max$ & 1.00 & 1.00 & 1.00 & 1.00 & $\max$ & 1.00 & 1.00 & 1.00 & 1.00 & $\max$ & 1.00 & 1.00 & 1.00 & 1.00 \\
\hline mean & 0.70 & 0.75 & 0.93 & 0.95 & mean & 0.90 & 0.92 & 0.97 & 0.98 & mean & 0.76 & 0.78 & 0.98 & 1.00 \\
\hline stdev & 0.18 & 0.18 & 0.10 & 0.10 & stdev & 0.15 & 0.13 & 0.05 & 0.04 & stdev & 0.18 & 0.17 & 0.05 & 0.00 \\
\hline $\min$ & 0.47 & 0.47 & 0.69 & 0.60 & $\min$ & 0.60 & 0.60 & 0.83 & 0.86 & $\min$ & 0.44 & 0.44 & 0.84 & 1.00 \\
\hline $\max$ & 1.00 & 1.00 & 1.00 & 1.00 & $\max$ & 1.00 & 1.00 & 1.00 & 1.00 & $\max$ & 1.00 & 1.00 & 1.00 & 1.00 \\
\hline mean & 0.77 & 0.79 & 0.97 & 0.97 & mean & 0.88 & 0.90 & 0.98 & 0.98 & mean & 0.83 & 0.84 & 0.98 & 0.99 \\
\hline stdev & 0.17 & 0.16 & 0.07 & 0.04 & stdev & 0.15 & 0.13 & 0.04 & 0.04 & stdev & 0.14 & 0.14 & 0.04 & 0.01 \\
\hline $\min$ & 0.50 & 0.50 & 0.71 & 0.86 & $\min$ & 0.61 & 0.63 & 0.85 & 0.85 & $\min$ & 0.52 & 0.52 & 0.85 & 0.96 \\
\hline $\max$ & 1.00 & 1.00 & 1.00 & 1.00 & $\max$ & 1.00 & 1.00 & 1.00 & 1.00 & $\max$ & 1.00 & 1.00 & 1.00 & 1.00 \\
\hline mean & 0.8 & 0.83 & 0.96 & 0.99 & Mean & 0.88 & 0.9 & 0.97 & 0.99 & mean & 0.75 & 0.75 & 1 & 1.00 \\
\hline stdev & 0.19 & 0.17 & 0.07 & 0.02 & stdev & 0.17 & 0.15 & 0.05 & 0.03 & stdev & 0.17 & 0.17 & 0 & 0.01 \\
\hline $\min$ & 0.52 & 0.53 & 0.73 & 0.92 & Min & 0.54 & 0.54 & 0.84 & 0.88 & $\min$ & 0.47 & 0.47 & 1 & 0.98 \\
\hline $\max$ & 1 & 1 & 1 & 1.00 & $\operatorname{Max}$ & 1 & 1 & 1 & 1.00 & $\max$ & 1 & 1 & 1 & 1.00 \\
\hline mean & 0.81 & 0.82 & 0.99 & 0.99 & mean & 0.92 & 0.93 & 0.99 & 1.00 & mean & 0.81 & 0.81 & 1.00 & 1.00 \\
\hline stdev & 0.17 & 0.17 & 0.03 & 0.02 & stdev & 0.13 & 0.12 & 0.02 & 0.00 & stdev & 0.15 & 0.15 & 0.00 & 0.00 \\
\hline $\min$ & 0.51 & 0.52 & 0.89 & 0.94 & $\min$ & 0.55 & 0.56 & 0.94 & 0.99 & $\min$ & 0.57 & 0.57 & 1.00 & 1.00 \\
\hline $\max$ & 1.00 & 1.00 & 1.00 & 1.00 & $\max$ & 1.00 & 1.00 & 1.00 & 1.00 & $\max$ & 1.00 & 1.00 & 1.00 & 1.00 \\
\hline mean & 0.84 & 0.86 & 0.98 & 0.99 & mean & 0.93 & 0.94 & 0.99 & 1.00 & mean & 0.82 & 0.82 & 1.00 & 1.00 \\
\hline stdev & 0.14 & 0.14 & 0.04 & 0.03 & stdev & 0.11 & 0.10 & 0.02 & 0.01 & stdev & 0.14 & 0.14 & 0.00 & 0.00 \\
\hline $\min$ & 0.56 & 0.56 & 0.86 & 0.88 & $\min$ & 0.71 & 0.71 & 0.91 & 0.97 & $\min$ & 0.64 & 0.64 & 1.00 & 0.99 \\
\hline $\max$ & 1.00 & 1.00 & 1.00 & 1.00 & $\max$ & 1.00 & 1.00 & 1.00 & 1.00 & $\max$ & 1.00 & 1.00 & 1.00 & 1.00 \\
\hline mean & 0.77 & 0.81 & 0.95 & 0.99 & mean & 0.93 & 0.94 & 0.99 & 0.99 & mean & 0.77 & 0.77 & 1.00 & 0.99 \\
\hline stdev & 0.19 & 0.16 & 0.11 & 0.02 & stdev & 0.13 & 0.12 & 0.03 & 0.02 & stdev & 0.14 & 0.14 & 0.01 & 0.04 \\
\hline $\min$ & 0.51 & 0.52 & 0.63 & 0.92 & $\min$ & 0.60 & 0.60 & 0.88 & 0.94 & $\min$ & 0.52 & 0.52 & 0.97 & 0.87 \\
\hline $\max$ & 1.00 & 1.00 & 1.00 & 1.00 & $\max$ & 1.00 & 1.00 & 1.00 & 1.00 & $\max$ & 1.00 & 1.00 & 1.00 & 1.00 \\
\hline mean & 0.47 & 0.49 & 0.96 & 0.99 & Mean & 0.68 & 0.69 & 0.98 & 0.96 & mean & 0.41 & 0.41 & 0.99 & 1.00 \\
\hline stdev & 0.26 & 0.25 & 0.09 & 0.03 & stdev & 0.31 & 0.3 & 0.04 & 0.06 & stdev & 0.27 & 0.27 & 0.05 & 0.00 \\
\hline $\min$ & 0.23 & 0.25 & 0.65 & 0.87 & Min & 0.21 & 0.21 & 0.88 & 0.84 & $\min$ & 0.19 & 0.19 & 0.82 & 0.99 \\
\hline $\max$ & 1 & 1 & 1 & 1.00 & Max & 1 & 1 & 1 & 1.00 & $\max$ & 1 & 1 & 1 & 1.00 \\
\hline mean & 0.78 & 0.80 & 0.97 & 0.98 & mean & 0.82 & 0.83 & 0.98 & 0.98 & mean & 0.78 & 0.84 & 0.94 & 0.98 \\
\hline stdev & 0.20 & 0.18 & 0.07 & 0.04 & stdev & 0.19 & 0.19 & 0.03 & 0.06 & stdev & 0.14 & 0.11 & 0.10 & 0.02 \\
\hline $\min$ & 0.46 & 0.46 & 0.74 & 0.87 & $\min$ & 0.43 & 0.45 & 0.89 & 0.82 & $\min$ & 0.56 & 0.66 & 0.73 & 0.92 \\
\hline $\max$ & 1.00 & 1.00 & 1.00 & 1.00 & $\max$ & 1.00 & 1.00 & 1.00 & 1.00 & $\max$ & 1.00 & 1.00 & 1.00 & 1.00 \\
\hline mean & 0.84 & 0.85 & 0.99 & 0.97 & mean & 0.87 & 0.88 & 0.98 & 0.97 & mean & 0.81 & 0.84 & 0.96 & 0.98 \\
\hline stdev & 0.16 & 0.16 & 0.04 & 0.09 & stdev & 0.18 & 0.16 & 0.04 & 0.07 & stdev & 0.16 & 0.14 & 0.07 & 0.03 \\
\hline $\min$ & 0.53 & 0.53 & 0.83 & 0.64 & $\min$ & 0.40 & 0.48 & 0.83 & 0.71 & $\min$ & 0.52 & 0.59 & 0.78 & 0.92 \\
\hline $\min$ & 1.00 & 1.00 & 1.00 & 1.00 & $\min$ & 1.00 & 1.00 & 1.00 & 1.00 & $\min$ & 1.00 & 1.00 & 1.00 & 1.00 \\
\hline mean & 0.80 & 0.81 & 0.98 & 0.97 & mean & 0.82 & 0.83 & 0.99 & 0.95 & mean & 0.85 & 0.89 & 0.96 & 0.95 \\
\hline stdev & 0.18 & 0.17 & 0.04 & 0.04 & stdev & 0.22 & 0.22 & 0.02 & 0.11 & stdev & 0.15 & 0.13 & 0.08 & 0.08 \\
\hline $\min$ & 0.55 & 0.56 & 0.86 & 0.88 & $\min$ & 0.21 & 0.21 & 0.92 & 0.57 & $\min$ & 0.61 & 0.66 & 0.74 & 0.73 \\
\hline $\min$ & 1.00 & 1.00 & 1.00 & 1.00 & $\min$ & 1.00 & 1.00 & 1.00 & 1.00 & $\min$ & 1.00 & 1.00 & 1.00 & 1.00 \\
\hline mean & 0.67 & 0.69 & 0.97 & 0.98 & mean & 0.86 & 0.87 & 0.98 & 0.99 & mean & 0.72 & 0.73 & 0.99 & 0.99 \\
\hline stdev & 0.23 & 0.22 & 0.06 & 0.04 & stdev & 0.14 & 0.14 & 0.04 & 0.03 & stdev & 0.17 & 0.16 & 0.02 & 0.02 \\
\hline $\min$ & 0.20 & 0.20 & 0.78 & 0.84 & $\min$ & 0.60 & 0.60 & 0.89 & 0.90 & $\min$ & 0.43 & 0.43 & 0.95 & 0.95 \\
\hline $\min$ & 1.00 & 1.00 & 1.00 & 1.00 & $\min$ & 1.00 & 1.00 & 1.00 & 1.00 & $\min$ & 1.00 & 1.00 & 1.00 & 1.00 \\
\hline mean & 0.80 & 0.80 & 0.99 & 0.99 & mean & 0.89 & 0.89 & 0.99 & 0.99 & mean & 0.78 & 0.78 & 1.00 & 0.99 \\
\hline stdev & 0.19 & 0.18 & 0.04 & 0.02 & stdev & 0.15 & 0.14 & 0.03 & 0.04 & stdev & 0.16 & 0.16 & 0.01 & 0.03 \\
\hline $\min$ & 0.41 & 0.49 & 0.85 & 0.94 & $\min$ & 0.56 & 0.56 & 0.91 & 0.86 & $\min$ & 0.51 & 0.51 & 0.97 & 0.88 \\
\hline $\min$ & 1.00 & 1.00 & 1.00 & 1.00 & $\min$ & 1.00 & 1.00 & 1.00 & 1.00 & $\min$ & 1.00 & 1.00 & 1.00 & 1.00 \\
\hline mean & 0.78 & 0.78 & 1 & 0.98 & mean & 0.91 & 0.92 & 0.98 & 0.97 & mean & 0.83 & 0.83 & 1.00 & 0.97 \\
\hline stdev & 0.2 & 0.2 & 0.01 & 0.06 & stdev & 0.13 & 0.11 & 0.05 & 0.03 & stdev & 0.15 & 0.15 & 0.00 & 0.07 \\
\hline $\min$ & 0.48 & 0.48 & 0.95 & 0.72 & $\min$ & 0.59 & 0.7 & 0.84 & 0.88 & $\min$ & 0.48 & 0.48 & 1.00 & 0.76 \\
\hline $\min$ & 1 & 1 & 1 & 1.00 & $\min$ & 1 & 1 & 1 & 1.00 & $\min$ & 1 & 1 & 1.00 & 1.00 \\
\hline
\end{tabular}


Table 5:

Total factor productivity (TFP), efficiency change (EC), technological change (TC) For all sample (45 obs), only FINED =1 companies (27 obs), FINED =1 specialist (12 obs), FINED $=1$ generalist $(15 \mathrm{obs})$ and Not FINED (18 obs)

\begin{tabular}{|c|c|c|c|c|c|c|c|c|}
\hline & \multicolumn{4}{|c|}{$\begin{array}{l}\text { All sample } \\
\text { (45 obs) }\end{array}$} & \multicolumn{4}{|c|}{$\begin{array}{c}\text { Fined } \\
(27 \text { obs })\end{array}$} \\
\hline & & TFP & EC & TC & & TFP & EC & TC \\
\hline \multirow[t]{4}{*}{$1982 \backslash 1983$} & mean & 1.00 & 1.04 & 0.95 & mean & 0.99 & 1.05 & 0.95 \\
\hline & stdev & 0.21 & 0.08 & 0.17 & stdev & 0.14 & 0.06 & 0.12 \\
\hline & $\min$ & 0.11 & 0.81 & 0.11 & $\min$ & 0.60 & 0.95 & 0.60 \\
\hline & $\min$ & 1.69 & 1.26 & 1.24 & $\min$ & 1.30 & 1.15 & 1.18 \\
\hline \multirow[t]{4}{*}{$1983 \backslash 1984$} & mean & 1.02 & 1.02 & 1.00 & mean & 1.02 & 1.02 & 1.00 \\
\hline & stdev & 0.15 & 0.07 & 0.12 & stdev & 0.12 & 0.06 & 0.10 \\
\hline & $\min$ & 0.61 & 0.88 & 0.61 & $\min$ & 0.73 & 0.88 & 0.73 \\
\hline & $\min$ & 1.33 & 1.24 & 1.28 & $\min$ & 1.28 & 1.18 & 1.28 \\
\hline \multirow[t]{4}{*}{$1984 \backslash 1985$} & mean & 0.99 & 0.98 & 1.01 & mean & 1.02 & 1.00 & 1.02 \\
\hline & stdev & 0.14 & 0.09 & 0.09 & stdev & 0.06 & 0.05 & 0.03 \\
\hline & $\min$ & 0.57 & 0.65 & 0.76 & $\min$ & 0.88 & 0.87 & 0.92 \\
\hline & $\min$ & 1.44 & 1.13 & 1.34 & $\min$ & 1.18 & 1.13 & 1.07 \\
\hline \multirow[t]{4}{*}{$1985 \backslash 1986$} & mean & 1.02 & 1.02 & 1.00 & mean & 1.00 & 1.01 & 0.99 \\
\hline & stdev & 0.25 & 0.08 & 0.16 & stdev & 0.08 & 0.04 & 0.07 \\
\hline & $\min$ & 0.58 & 0.90 & 0.61 & $\min$ & 0.78 & 0.94 & 0.78 \\
\hline & $\min$ & 2.42 & 1.37 & 1.83 & $\min$ & 1.19 & 1.13 & 1.08 \\
\hline \multirow[t]{4}{*}{$1986 \backslash 1987$} & mean & 0.99 & 1.00 & 0.99 & mean & 0.98 & 1.00 & 0.98 \\
\hline & stdev & 0.14 & 0.06 & 0.13 & stdev & 0.12 & 0.04 & 0.09 \\
\hline & $\min$ & 0.62 & 0.82 & 0.62 & $\min$ & 0.72 & 0.88 & 0.72 \\
\hline & $\min$ & 1.42 & 1.21 & 1.42 & $\min$ & 1.37 & 1.13 & 1.20 \\
\hline \multirow[t]{4}{*}{$1987 \backslash 1988$} & mean & 1.01 & 0.98 & 1.03 & mean & 1.00 & 0.99 & 1.01 \\
\hline & stdev & 0.15 & 0.11 & 0.10 & stdev & 0.08 & 0.04 & 0.07 \\
\hline & $\min$ & 0.54 & 0.50 & 0.82 & $\min$ & 0.87 & 0.84 & 0.88 \\
\hline & $\min$ & 1.42 & 1.21 & 1.35 & $\min$ & 1.15 & 1.04 & 1.15 \\
\hline $1988 \backslash 1989$ & mean & 1.07 & 1.04 & 1.02 & mean & 1.04 & 1.01 & 1.02 \\
\hline & stdev & 0.19 & 0.14 & 0.10 & stdev & 0.08 & 0.04 & 0.07 \\
\hline & $\min$ & 0.80 & 0.86 & 0.82 & $\min$ & 0.88 & 0.95 & 0.92 \\
\hline & $\min$ & 1.88 & 1.73 & 1.34 & $\min$ & 1.20 & 1.15 & 1.20 \\
\hline $1989 \backslash 1990$ & mean & 1.04 & 1.01 & 1.02 & mean & 1.03 & 1.01 & 1.02 \\
\hline & stdev & 0.14 & 0.06 & 0.09 & stdev & 0.09 & 0.05 & 0.07 \\
\hline & $\min$ & 0.75 & 0.88 & 0.77 & $\min$ & 0.84 & 0.88 & 0.84 \\
\hline & $\min$ & 1.54 & 1.19 & 1.21 & $\min$ & 1.24 & 1.19 & 1.15 \\
\hline $1991 \backslash 1990$ & mean & 1.04 & 0.98 & 1.06 & mean & 1.01 & 0.98 & 1.03 \\
\hline & stdev & 0.11 & 0.05 & 0.09 & stdev & 0.08 & 0.04 & 0.08 \\
\hline & $\min$ & 0.82 & 0.82 & 0.90 & $\min$ & 0.88 & 0.88 & 0.90 \\
\hline & $\min$ & 1.33 & 1.03 & 1.33 & $\min$ & 1.19 & 1.00 & 1.19 \\
\hline $1991 \backslash 1992$ & mean & 0.97 & 1.00 & 0.97 & mean & 0.95 & 1.00 & 0.95 \\
\hline & stdev & 0.13 & 0.04 & 0.12 & stdev & 0.08 & 0.01 & 0.08 \\
\hline & $\min$ & 0.67 & 0.85 & 0.76 & $\min$ & 0.81 & 0.97 & 0.81 \\
\hline & $\min$ & 1.47 & 1.10 & 1.47 & $\min$ & 1.13 & 1.03 & 1.13 \\
\hline $1992 \backslash 1993$ & mean & 1.09 & 0.98 & 1.11 & mean & 1.13 & 0.99 & 1.14 \\
\hline & stdev & 0.16 & 0.07 & 0.13 & stdev & 0.13 & 0.03 & 0.12 \\
\hline & $\min$ & 0.65 & 0.69 & 0.87 & $\min$ & 0.84 & 0.86 & 0.90 \\
\hline & $\min$ & 1.40 & 1.05 & 1.40 & $\min$ & 1.40 & 1.03 & 1.40 \\
\hline $1993 \backslash 1994$ & mean & 1.09 & 0.99 & 1.11 & mean & 1.14 & 0.98 & 1.16 \\
\hline & stdev & 0.27 & 0.07 & 0.26 & stdev & 0.32 & 0.05 & 0.31 \\
\hline & $\min$ & 0.81 & 0.81 & 0.81 & $\min$ & 0.82 & 0.81 & 0.82 \\
\hline & $\min$ & 2.16 & 1.19 & 2.16 & $\min$ & 2.16 & 1.06 & 2.16 \\
\hline $1994 \backslash 1995$ & mean & 1.20 & 1.00 & 1.20 & mean & 1.23 & 0.98 & 1.24 \\
\hline & stdev & 0.41 & 0.13 & 0.33 & stdev & 0.44 & 0.12 & 0.36 \\
\hline & $\min$ & 0.40 & 0.77 & 0.44 & $\min$ & 0.40 & 0.77 & 0.44 \\
\hline & $\min$ & 2.24 & 1.54 & 2.02 & $\min$ & 2.05 & 1.23 & 2.02 \\
\hline $1995 \backslash 1996$ & mean & 1.03 & 1.01 & 1.02 & mean & 1.05 & 1.01 & 1.04 \\
\hline & stdev & 0.17 & 0.12 & 0.14 & stdev & 0.15 & 0.11 & 0.13 \\
\hline & $\min$ & 0.58 & 0.64 & 0.75 & $\min$ & 0.75 & 0.71 & 0.75 \\
\hline & $\min$ & 1.44 & 1.43 & 1.38 & $\min$ & 1.37 & 1.43 & 1.37 \\
\hline $1996 \backslash 1997$ & mean & 1.21 & 0.99 & 1.23 & mean & 1.16 & 0.98 & 1.18 \\
\hline & stdev & 0.36 & 0.09 & 0.33 & stdev & 0.33 & 0.09 & 0.29 \\
\hline & $\min$ & 0.52 & 0.73 & 0.52 & $\min$ & 0.52 & 0.73 & 0.52 \\
\hline & $\min$ & 2.32 & 1.26 & 2.32 & $\min$ & 2.32 & 1.26 & 2.32 \\
\hline $1997 \backslash 1998$ & mean & 1.20 & 1.20 & 1.15 & mean & 1.17 & 1.20 & 1.09 \\
\hline & stdev & 0.69 & 0.55 & 0.70 & stdev & 0.65 & 0.50 & 0.64 \\
\hline & $\min$ & 0.38 & 0.78 & 0.38 & $\min$ & 0.38 & 0.90 & 0.38 \\
\hline & $\min$ & 3.92 & 3.50 & 3.92 & $\min$ & 3.92 & 3.50 & 3.92 \\
\hline $1998 \backslash 1999$ & mean & 1.05 & 1.00 & 1.05 & mean & 0.97 & 0.99 & 0.97 \\
\hline & stdev & 0.28 & 0.05 & 0.28 & stdev & 0.11 & 0.03 & 0.10 \\
\hline & $\min$ & 0.72 & 0.86 & 0.72 & $\min$ & 0.72 & 0.88 & 0.72 \\
\hline & $\min$ & 2.28 & 1.18 & 2.28 & $\min$ & 1.24 & 1.05 & 1.17 \\
\hline $1999 \backslash 2000$ & mean & 1.02 & 0.99 & 1.03 & mean & 0.96 & 0.98 & 0.97 \\
\hline & stdev & 0.17 & 0.08 & 0.15 & stdev & 0.10 & 0.07 & 0.07 \\
\hline & $\min$ & 0.74 & 0.72 & 0.81 & $\min$ & 0.74 & 0.76 & 0.81 \\
\hline & $\min$ & 1.73 & 1.16 & 1.73 & $\min$ & 1.09 & 1.09 & 1.07 \\
\hline
\end{tabular}




\begin{tabular}{|c|c|c|c|c|c|c|c|c|c|c|c|}
\hline \multicolumn{4}{|c|}{$\begin{array}{l}\text { Fined - generalist } \\
\text { (15 obs) }\end{array}$} & \multicolumn{4}{|c|}{$\begin{array}{c}\text { Fined - specialist } \\
(12 \text { obs })\end{array}$} & \multicolumn{4}{|c|}{$\begin{array}{l}\text { Not fined } \\
(18 \text { obs })\end{array}$} \\
\hline & TFP & EC & TC & & TFP & EC & TC & & TFP & EC & TC \\
\hline mean & 0.98 & 1.04 & 0.93 & mean & 1.00 & 1.04 & 0.96 & mean & 1.02 & 1.03 & 0.95 \\
\hline stdev & 0.12 & 0.06 & 0.10 & stdev & 0.15 & 0.05 & 0.13 & stdev & 0.29 & 0.10 & 0.23 \\
\hline $\min$ & 0.60 & 0.95 & 0.60 & $\min$ & 0.60 & 0.97 & 0.60 & $\min$ & 0.11 & 0.81 & 0.11 \\
\hline $\min$ & 1.13 & 1.15 & 1.02 & $\min$ & 1.30 & 1.13 & 1.18 & $\min$ & 1.69 & 1.26 & 1.24 \\
\hline mean & 1.04 & 1.04 & 1.00 & mean & 1.01 & 1.00 & 1.01 & mean & 1.00 & 1.02 & 1.00 \\
\hline stdev & 0.11 & 0.07 & 0.10 & stdev & 0.13 & 0.05 & 0.11 & stdev & 0.18 & 0.08 & 0.14 \\
\hline $\min$ & 0.73 & 0.88 & 0.73 & $\min$ & 0.74 & 0.89 & 0.84 & $\min$ & 0.61 & 0.91 & 0.61 \\
\hline $\min$ & 1.22 & 1.18 & 1.11 & $\min$ & 1.28 & 1.09 & 1.28 & $\min$ & 1.33 & 1.24 & 1.23 \\
\hline mean & 1.02 & 1.00 & 1.02 & mean & 1.03 & 1.01 & 1.02 & mean & 0.95 & 0.94 & 0.99 \\
\hline stdev & 0.04 & 0.03 & 0.03 & stdev & 0.08 & 0.06 & 0.04 & stdev & 0.21 & 0.12 & 0.14 \\
\hline $\min$ & 0.97 & 0.96 & 0.97 & $\min$ & 0.88 & 0.87 & 0.92 & $\min$ & 0.57 & 0.65 & 0.76 \\
\hline $\min$ & 1.13 & 1.05 & 1.07 & $\min$ & 1.18 & 1.13 & 1.06 & $\min$ & 1.44 & 1.07 & 1.34 \\
\hline mean & 1.02 & 1.01 & 1.01 & mean & 1.00 & 1.02 & 0.98 & mean & 1.05 & 1.04 & 1.00 \\
\hline stdev & 0.08 & 0.03 & 0.05 & stdev & 0.05 & 0.04 & 0.06 & stdev & 0.37 & 0.12 & 0.24 \\
\hline $\min$ & 0.87 & 0.94 & 0.88 & $\min$ & 0.93 & 0.94 & 0.88 & $\min$ & 0.58 & 0.90 & 0.61 \\
\hline $\min$ & 1.19 & 1.10 & 1.08 & $\min$ & 1.10 & 1.13 & 1.08 & $\min$ & 2.42 & 1.37 & 1.83 \\
\hline mean & 0.97 & 1.00 & 0.97 & mean & 0.96 & 1.00 & 0.95 & mean & 1.02 & 1.00 & 1.02 \\
\hline stdev & 0.08 & 0.04 & 0.07 & stdev & 0.15 & 0.04 & 0.12 & stdev & 0.18 & 0.09 & 0.16 \\
\hline $\min$ & 0.72 & 0.88 & 0.72 & $\min$ & 0.72 & 0.93 & 0.72 & $\min$ & 0.62 & 0.82 & 0.62 \\
\hline $\min$ & 1.05 & 1.08 & 1.06 & $\min$ & 1.37 & 1.13 & 1.20 & $\min$ & 1.42 & 1.21 & 1.42 \\
\hline mean & 1.01 & 0.99 & 1.02 & mean & 0.99 & 0.99 & 1.00 & mean & 1.04 & 0.98 & 1.06 \\
\hline stdev & 0.08 & 0.04 & 0.07 & stdev & 0.06 & 0.03 & 0.05 & stdev & 0.22 & 0.17 & 0.12 \\
\hline $\min$ & 0.87 & 0.84 & 0.88 & $\min$ & 0.88 & 0.89 & 0.88 & $\min$ & 0.54 & 0.50 & 0.82 \\
\hline $\min$ & 1.15 & 1.04 & 1.15 & $\min$ & 1.09 & 1.04 & 1.09 & $\min$ & 1.42 & 1.21 & 1.35 \\
\hline mean & 1.04 & 1.02 & 1.02 & mean & 1.04 & 1.01 & 1.03 & mean & 1.12 & 1.09 & 1.01 \\
\hline stdev & 0.07 & 0.04 & 0.05 & stdev & 0.08 & 0.01 & 0.08 & stdev & 0.28 & 0.22 & 0.14 \\
\hline $\min$ & 0.92 & 0.95 & 0.92 & $\min$ & 0.93 & 1.00 & 0.93 & $\min$ & 0.80 & 0.86 & 0.82 \\
\hline $\min$ & 1.18 & 1.15 & 1.11 & $\min$ & 1.20 & 1.04 & 1.20 & $\min$ & 1.88 & 1.73 & 1.34 \\
\hline mean & 1.04 & 0.99 & 1.04 & mean & 1.01 & 1.02 & 1.00 & mean & 1.06 & 1.01 & 1.02 \\
\hline stdev & 0.07 & 0.04 & 0.06 & stdev & 0.10 & 0.06 & 0.08 & stdev & 0.19 & 0.07 & 0.12 \\
\hline $\min$ & 0.94 & 0.88 & 0.94 & $\min$ & 0.84 & 0.95 & 0.84 & $\min$ & 0.75 & 0.88 & 0.77 \\
\hline $\min$ & 1.15 & 1.06 & 1.15 & $\min$ & 1.24 & 1.19 & 1.14 & $\min$ & 1.54 & 1.15 & 1.21 \\
\hline mean & 1.01 & 0.97 & 1.04 & mean & 1.04 & 0.99 & 1.05 & mean & 1.07 & 0.97 & 1.09 \\
\hline stdev & 0.08 & 0.04 & 0.07 & stdev & 0.08 & 0.02 & 0.09 & stdev & 0.13 & 0.06 & 0.10 \\
\hline $\min$ & 0.88 & 0.88 & 0.90 & $\min$ & 0.94 & 0.92 & 0.94 & $\min$ & 0.82 & 0.82 & 0.97 \\
\hline $\min$ & 1.18 & 1.00 & 1.18 & $\min$ & 1.19 & 1.00 & 1.19 & $\min$ & 1.33 & 1.03 & 1.33 \\
\hline mean & 0.92 & 1.00 & 0.92 & mean & 0.97 & 1.00 & 0.97 & mean & 0.99 & 0.99 & 1.00 \\
\hline stdev & 0.06 & 0.01 & 0.06 & stdev & 0.07 & 0.01 & 0.07 & stdev & 0.19 & 0.06 & 0.17 \\
\hline $\min$ & 0.81 & 0.97 & 0.81 & $\min$ & 0.87 & 0.97 & 0.87 & $\min$ & 0.67 & 0.85 & 0.76 \\
\hline $\min$ & 1.04 & 1.03 & 1.04 & $\min$ & 1.11 & 1.01 & 1.11 & $\min$ & 1.47 & 1.10 & 1.47 \\
\hline mean & 1.18 & 1.00 & 1.19 & mean & 1.08 & 0.99 & 1.09 & mean & 1.01 & 0.97 & 1.05 \\
\hline stdev & 0.12 & 0.02 & 0.11 & stdev & 0.12 & 0.04 & 0.10 & stdev & 0.18 & 0.10 & 0.12 \\
\hline $\min$ & 1.05 & 0.94 & 1.05 & $\min$ & 0.84 & 0.86 & 0.90 & $\min$ & 0.65 & 0.69 & 0.87 \\
\hline $\min$ & 1.40 & 1.03 & 1.40 & $\min$ & 1.27 & 1.03 & 1.27 & $\min$ & 1.27 & 1.05 & 1.27 \\
\hline mean & 1.17 & 0.96 & 1.21 & mean & 1.13 & 0.99 & 1.14 & mean & 1.03 & 1.01 & 1.03 \\
\hline stdev & 0.31 & 0.06 & 0.28 & stdev & 0.35 & 0.04 & 0.34 & stdev & 0.14 & 0.08 & 0.13 \\
\hline $\min$ & 0.92 & 0.81 & 0.99 & $\min$ & 0.82 & 0.90 & 0.82 & $\min$ & 0.81 & 0.87 & 0.81 \\
\hline $\min$ & 1.83 & 1.03 & 1.83 & $\min$ & 2.16 & 1.06 & 2.16 & $\min$ & 1.36 & 1.19 & 1.36 \\
\hline mean & 1.47 & 1.02 & 1.43 & mean & 0.98 & 0.93 & 1.06 & mean & 1.15 & 1.02 & 1.13 \\
\hline stdev & 0.43 & 0.13 & 0.35 & stdev & 0.23 & 0.10 & 0.23 & stdev & 0.36 & 0.15 & 0.24 \\
\hline $\min$ & 0.64 & 0.78 & 0.64 & $\min$ & 0.40 & 0.77 & 0.44 & $\min$ & 0.73 & 0.84 & 0.73 \\
\hline $\min$ & 2.05 & 1.23 & 2.02 & $\min$ & 1.46 & 1.11 & 1.34 & $\min$ & 2.24 & 1.54 & 1.74 \\
\hline mean & 1.09 & 0.99 & 1.10 & mean & 1.03 & 1.04 & 0.99 & mean & 1.00 & 1.01 & 1.00 \\
\hline stdev & 0.14 & 0.09 & 0.11 & stdev & 0.13 & 0.12 & 0.10 & stdev & 0.20 & 0.14 & 0.14 \\
\hline $\min$ & 0.80 & 0.71 & 0.98 & $\min$ & 0.77 & 0.91 & 0.77 & $\min$ & 0.58 & 0.64 & 0.75 \\
\hline $\min$ & 1.37 & 1.15 & 1.37 & $\min$ & 1.35 & 1.43 & 1.22 & $\min$ & 1.44 & 1.39 & 1.38 \\
\hline mean & 1.21 & 0.99 & 1.21 & mean & 1.15 & 0.99 & 1.16 & mean & 1.28 & 1.00 & 1.32 \\
\hline stdev & 0.43 & 0.09 & 0.37 & stdev & 0.27 & 0.11 & 0.15 & stdev & 0.38 & 0.08 & 0.36 \\
\hline $\min$ & 0.52 & 0.81 & 0.52 & $\min$ & 0.92 & 0.73 & 0.98 & $\min$ & 0.89 & 0.85 & 0.89 \\
\hline $\min$ & 2.32 & 1.26 & 2.32 & $\min$ & 2.03 & 1.26 & 1.62 & $\min$ & 2.32 & 1.26 & 2.32 \\
\hline mean & 0.99 & 1.06 & 0.92 & mean & 1.37 & 1.34 & 1.28 & mean & 1.26 & 1.18 & 1.26 \\
\hline stdev & 0.40 & 0.19 & 0.32 & stdev & 0.79 & 0.66 & 0.81 & stdev & 0.75 & 0.63 & 0.78 \\
\hline $\min$ & 0.38 & 0.90 & 0.38 & $\min$ & 0.84 & 1.00 & 0.84 & $\min$ & 0.41 & 0.78 & 0.52 \\
\hline $\min$ & 1.90 & 1.75 & 1.73 & $\min$ & 3.92 & 3.50 & 3.92 & $\min$ & 3.92 & 3.50 & 3.92 \\
\hline mean & 0.98 & 0.99 & 0.99 & mean & 0.96 & 0.99 & 0.96 & mean & 1.18 & 1.02 & 1.18 \\
\hline stdev & 0.08 & 0.02 & 0.09 & stdev & 0.12 & 0.05 & 0.08 & stdev & 0.38 & 0.07 & 0.40 \\
\hline $\min$ & 0.82 & 0.95 & 0.82 & $\min$ & 0.79 & 0.88 & 0.87 & $\min$ & 0.86 & 0.86 & 0.86 \\
\hline $\min$ & 1.12 & 1.03 & 1.12 & $\min$ & 1.24 & 1.05 & 1.17 & $\min$ & 2.28 & 1.18 & 2.28 \\
\hline mean & 0.96 & 0.98 & 0.98 & mean & 0.96 & 0.99 & 0.98 & mean & 1.13 & 1.00 & 1.12 \\
\hline stdev & 0.10 & 0.06 & 0.06 & stdev & 0.10 & 0.08 & 0.09 & stdev & 0.21 & 0.09 & 0.20 \\
\hline $\min$ & 0.74 & 0.81 & 0.85 & $\min$ & 0.80 & 0.76 & 0.81 & $\min$ & 0.81 & 0.72 & 0.90 \\
\hline $\min$ & 1.09 & 1.06 & 1.06 & $\min$ & 1.06 & 1.09 & 1.07 & $\min$ & 1.73 & 1.16 & 1.73 \\
\hline
\end{tabular}


companies), specialist insurers (12 companies) present in several years higher pure technical efficiency, but for the whole period they show lower cost and allocative efficiencies in respect to generalist insurers (15 companies). The possibility of overcoming difficulties in the motor line and in the other non-life lines with a higher efficiency in the life line probably explains these differences.

Several interesting results emerge from the Malmquist total factor productivity analysis. First of all, we observe that the companies in the sample did not experience strong variations either in the efficiency change dimension or in the technological change dimension during the period 1982-1993. After 1993, we observe an increase in total factor productivity at significant rates 9 per cent (1993/94), 20 per cent (1994/95), 21 per cent (1996/97), and 20 per cent (1997/98). These increments are mainly due to technological changes (shift in the curve) rather than to efficiency changes. This is consistent with the deep process of reorganization of companies at the administrative and distribution levels, and the re-structuring of operative activities, also promoted by the more diffuse introduction of modern information and communication technologies. The reduction in increments observed in 1998/1999 and 1999/2000 could be connected to changes in the accountability system introduced in $1998 .{ }^{11}$

Secondly, the comparison between fined and non-fined companies shows that the variations in total factor productivity are quite similar up to the early 1990s. Then, in the second half of the 1990s, non-fined companies present better results, especially with regard to the technological change dimension. It could be argued that higher competitive pressures in the motor business after 1994 produced a stronger incentive to pursue the introduction of real innovations in companies not participating in the information network established among fined insurers.

Among fined companies, generalist ones present better results than specialist ones in terms of total factor productivity, especially because of a higher increase in the technological change dimension. We could hypothesize that the technological innovations introduced by companies operating also in the life business (probably because of the innovation required by the strong dynamics observed in the life business) also benefited the non-life activities.

\section{Main conclusions}

In this paper we have tried to provide empirical evidence on how deregulation can shape market structure and industry performance. In order to do that, we analysed the evolution of the number of motor insurers, their entry-exit dynamics, the concentration ratios, the trend of premiums, and their relation to legislative events over the period 19822000. From this analysis we could conclude that the deregulation process activated in the insurance business in 1994 affected the Italian motor insurance industry. After 1994 the dynamics of entry-exit were particularly active and the number of authorized insurers clearly fell (from 97 in 1982, it went up to 113 in 1991, it went down to 105 in 1994 and it reached its minimum in 2000 with 80 companies, representing a fall of 23.8 per cent in only six years).

This downward trend in the number of competitors in the motor business observed in

11 We are investigating in more detail the possible effects of this accounting innovation. 
the second half of the 1990s is particularly significant, as it comes after a period of almost 15 years of constant growth.

Moreover, from the efficiency analysis carried out on a sample of 45 Italian insurers active in the motor insurance business, it seems that cost efficiency and in particular total factor productivity increased in the period considered (1982-2000), especially in the second half of the 1990s.

However, in order to derive definitive policy implications from the analysis suggested in this paper, it is still necessary to run further elaborations and data processing and to provide extra empirical evidence. Nevertheless, we think that to measure the extent, dispersion and interaction among deregulation measures and the dynamics of efficiency and productivity of insurers over time could give the regulators very helpful information. Several directions for future research are possible. Whether and to what extent the new structure of the market and the improvement of efficiency and productivity benefited and will benefit customers, are probably the most important questions to address.

\section{REFERENCES}

ASSICURAZIONI GENERALI, 2003, “Italian Market Trends: 2002”, Research Department.

BERGER, A.N. and HUMPHREY, D.B., 1992, "Measurement and Efficiency Issues in Commercial Banking”, in Griliches, Z. (ed.), Output Measurement in the Service Sectors. Chicago: University of Chicago Press.

BERGER, A.N. and HUMPHREY, D.B., 1997, "Efficiency of Financial Institutions: International Survey and Directions for Future Research”, European Journal of Operational Research, 98, pp. 175-213.

BERGER, A.N., CUMMINS, J.D. and WEISS, M.A., 1997, “The Coexistence of Multiple Distribution Systems for Financial Services: The Case of Property-Liability Insurance”, Journal of Business, 70, pp. 515-546.

BORGHESI, A., 1991, "Some Considerations on Productivity and Performance in Insurance", The Geneva Papers on Risk and Insurance, 16(60), July, pp. 293-301.

CHARNES, A., COOPER, W., LEWIN, A.Y. and SEIFORD, L.M., 1994, Data Envelopment Analysis: Theory, Methodology, and Applications. Norwell, MA: Kluwer Academic.

CLEVELAND, W.S., 1993, Visualizing Data. Summit, NJ: Hobart Press.

CLEVELAND, W.S., 1994, The Elements of Graphing Data. Summit, NJ: Hobart Press.

COOPER, W.W., SEIFORD, L.M. and TONE, K., 1999, Data Envelopment Analysis: A Comprehensive Text with Models, Applications, References and DEA-Solver Software. Boston: Kluwer Academic.

CUMMINS, J.D. and RUBIO-MISAS, M., 2001, "Deregulation, Consolidation and Efficiency: Evidence from the Spanish Insurance Industry”, Working Paper 02-01, Financial Institutions Center, The Wharton School, University of Pennsylvania.

CUMMINS, J.D., TURCHETTI, G. and WEISS, M.A., 1996, "Productivity and Technical Efficiency in the Italian Insurance Industry", Working Paper 96-10, Financial Institutions Center, The Wharton School, University of Pennsylvania.

CUMMINS, J.D., WEISS, M.A. and ZI, H., 1999, “Organizational Form and Efficiency: An Analysis of Stock and Mutual Property-Liability Insurers”, Management Science, 45, pp. 1254-1269.

FÄRE, R., GROSSKOPF, S., NORRIS, M. and ZHANG, Z., 1994, "Productivity Growth, Technical Progress, and Efficiency Change in Industrialized Countries", American Economic Review, 84, pp. 66-83.

FARRELL, M.J., 1957, "The Measurement of the Productive Efficiency", Journal of the Royal Statistical Society, Series A, CXX, Part 3, pp. 253-290.

GROSSKOPF, S., 1993, "Efficiency and Productivity”, in Fried, H.O., Lovell, C.A.K. and Schmidt, S.S. (eds), The Measurement of Productive Efficiency. New York: Oxford University Press.

ISVAP, 2000, “Motor Insurance in Italy: Analysis and Suggestions" (in Italian).

LOVELL, C.A.K., 1993, "Production Frontiers and Productive Efficiency," in Fried, H.O., Lovell, C.A.K. and Schmidt, S.S. (eds), The Measurement of Productive Efficiency. New York: Oxford University Press.

PONTREMOLI, R., 2002, "Evolution and Innovation in Insurance Management: the Italian Case", The Geneva Papers on Risk and Insurance, 27(4), pp. 669-687.

PROSPERETTI, L., 1991, "Economies of Scale in Italian non-Life Insurance", The Geneva Papers on Risk and Insurance, 16(60), pp. 282-292.

SKOGH, G., 1982, "Return to Scale in the Swedish Property-Liability Insurance Industry", The Journal of Risk and Insurance. 
SWISS RE, 1996, "Deregulation and Liberalisation of Market Access: the European Insurance Industry on the Threshold of a New Era in Competition", Sigma, 7.

TURCHETTI, G., 2000, Innovation and Distribution Channels in the Insurance Sector. Theoretical Analysis and Strategic Behaviour (in Italian). Milan: FrancoAngeli.

VARALDO, R. and TURCHETTI, G. (eds), 2000, Evolution Profiles of Marketing and Distribution of Insurance (in Italian). Milan: FrancoAngeli. 